\title{
O Direito Comparado no Curso de Pós-Graduação
}

\author{
J. Cretella Júnior \\ Professor Titular de Direito Administrativo \\ na Universidade de São Paulo.
}

\begin{abstract}
Síntese: 1. Introdução. 2. Direito comparado. 3. Confronto de institutos juridicos. 4. Instituto personativo. 5. Confronto de "ramos do direito" 6. Confronto de direitos". 7. Confronto de "sistemas jurídicos" 8. Cursos monográficos rotativos. 9. Conclusão.
\end{abstract}

\section{Introdução}

Nos Cursos de Mestrado e de Doutorado em direito Cursos de Pós-Graduação -, a orientação de modo algum poderá coincidir com a que se imprime ao Curso de Bacharelado, já que Doutorado e Bacharelado não são o mesmo curso, apenas em dois graus quantitativamente diversos: o objeto, o método de ensino, os objetivos visados são outros.

Não tem sentido, realmente, aumentar apenas a dosagem do curso especializado e desenvolver os mesmos temas - objeto -, empregando os mesmos métodos de exposição - dedutivo ou indutivo - , procurando, por fim, formar advogados militantes mais bem informados teoricamente, juízes mais clarividentes e procuradores com perspectivas mais amplas.

A finalidade do Curso de Pós-Graduação é muito mais profunda do que a de formar advogados, magistrados e procuradores, porque o Doutorado não é um Curso de Graduação em segunda instância, com matéria repetida e exposta com o mesmo método.

Qualitativamente diversos, o traço diferencial entre ambos é a "substância", a "matéria prima" e o modo de tratá-la, jamais a dosagem no tratamento.

Ontologicamente, o Curso de Pós-Graduação deverá ter, sem dúvida, ótica diversa, parâmetros distanciados do curso 
anterior, dimensão nova, já que a matéria-prima Direito objeto material - será apresentada em plano universal, mediante CONFRONTO, transcendendo o direito do país, em que se estuda, para atingir outras espécies, em perspectivas jamais suspeitadas.

O Curso de Bacharelado ou Curso de Graduação trabalha com matrizes conhecidas e estereotipadas, mostra "o que é" o direito, num dado momento e área geográfica, prende-se muito ao direito positivo local, resumindo-se em exposição dogmática, visando, sempre, a determinados resultados práticos imediatos, tão do gosto do moderno estudante.

Ao contrário, o Curso de Pós-Graduação, abstraindo e generalizando, procura atingir o "modelo jurídico", o "standard", o arquétipo indiferenciado, a forma jurídica pura, a categoria jurídica universal.

Por isso, "em segunda instância", além do objeto, o método e as finalidades são diferentes, porque, do contrário, repetimos, o Curso de Pós-Graduação deixaria de preencher o escopo em mira, caso consistisse em "aulas de reforço", em "aumento de dosagem", em reiteração de assuntos já tratados, em quadros nacionais restritos, em institutos limitados por dispositivos legais rígidos, em monografias exaustivas sobre temas já vistos.

Por todos esses motivos, o método de ensino, no Curso de Pós-Graduação, só pode, na primeira fase, ser um - o método comparativo, o confronto constante, o paralelo sincrônico e diacrônico entre realidades nacionais e estrangeiras, ou entre duas ou mais realidades estrangeiras. Na segunda fase, o confronto do resultado obtido com a realidade pátria.

\section{Direito comparado}

Direito comparado não é ramo do direito, como poderia parecer, num primeiro encontro com a expressão: é método. Direito comparado é método de exposição e de pesquisa, bașeado no CONFRONTo entre fenômenos jurídicos que se passam entre coletividades diversas.

Direito comparad'o é o método de investigação jurídica que confronta (a) institutos jurídicos, (b) ramos do direito, (c) direitos e (d), por fim, sistemas jurídicos. Eis o quádruplo objetivo do direito comparado. 


\section{Confronto de institutos jurídicos}

As normas jurídicas incidem sobre fatos do mundo ou sobre atos do homem, suporte fático dessas mesmas normas. Ao mundo do direito interessam as relações "hominis ad hominem", reguladas pelas normas jurídicas.

A cada feixe de normas disciplinadoras das relações de homem para homem, integrando-as na ordem jurídica, damos o nome de instituto jurídico. Por sua vez, os institutos jurídicos escalonam-se pela importância e generalidade, classificando-se em principais e secundários. Formam-se, dentro dos sistemas, núcleos de institutos que se interligam de maneira direta, recebendo o nome de principais, em relação aos que os sucedem, na relação descendente e secundários, quando postos em confronto com os que os precedem, na mesma escala, ascendentemente.

A noção de instituto jurídico, que alguns entendem como sinônimo de instituição jurídica, é fundamental, porque todos os sistemas de direito trabalham com normas e conjuntos de normas, que convergem para determinados pontos do sistema, orientando-se para fins comuns.

A unidade lógica das regras jurídicas, vigentes num dado Estado, é imperativo do espírito humano. As normas relativas às diversas relações jurídicas são agrupadas sistematicamente, formando os institutos jurídicos. A coordenação dos diferentes institutos jurídicos, em um todo harmônico, forma o "direito". Todo instituto jurídico tem, no respectivo direito, em que se insere, lugar próprio. Identificá-lo é determinar-lhe a natureza. Impõe-se a localização para melhor compreensão e exata aplicação das regras que o compõem.

A expressão instituto jurídico é empregada em duas acepções, ora para designar a matéria que constitui objeto da disciplinação jurídica normativa, ora para qualificar as próprias normas.

"Agrupam-se as regras em torno de núcleos, que são os institutos jurídicos. Instituto jurídico é o conjunto típico de relações organizadas pelo direito como, por exemplo, o casamento, a propriedade, o testamento, a eleição, o recurso judicial, o tratado internacional. Trata-se de instrumento indispensável à vida jurídica" (CLAUDE DU PASQUIER, Introduction à la théorie générale et à la philosophie du droit, $3 .^{\mathrm{a}}$ ed., 1948, pág. 141). 
Instituto jurídico é o conjunto de regras de direito que reciprocamente se penetram, a ponto de constituírem um todo orgânico, no qual se compreende uma série indefinida de relações de fato, logo transformadas em relações de direito. Todas essas relações se originam de um só fato fundamental, que não constitui, apenas, a origem e a base do instituto, senão, ainda, o elemento que lhe ordena a organização e o desenvolvimento. (Bonnecase, Introduction à l'étude du droit, pág. 80).

\section{Instituto personativo}

No Brasil, o estudo da pessoa toma como base o direito civil, cujo respectivo Código, no artigo segundo, é preciso ao identificar "homem" e "pessoa física" (todo homem é capaz de direitos e obrigações na ordem civil).

Quanto às pessoas jurídicas, os artigos 14 e 16 esgotam, inexoravelmente, as modalidades existentes entre nós.

o Curso de Graduação, em duas disciplinas, Direito Civil e Introdução à Ciência do Direito, explica e desenvolve a noção de pessoa, a definição e a divisão, bem como os atributos peculiares ao instituto personativo.

Esgotar-se-ia, porém, no âmbito dos vários "direitos positivos", o elenco das pessoas físicas e jurídicas? Pessoa física ou pessoa jurídica é apenas aquilo que o direito positivo dum país, nos quadros do Código Civil, define e enumera como tal?

Em direito administrativo, por exemplo, e, em direito constitucional, as pessoas jurídicas públicas, enumeradas pelo Código Civil pátrio são (a) a União, (b) cada um dos Estados-membros, (c) o Distrito Federal, (d) cada um dos Municípios, legalmente constituídos. Além dessas quatro pessoas jurídicas públicas (União, Distrito Federal, Município e Estado-membro), devemos ainda acrescentar a Autarquia.

Em síntese, o quadro do "direito positivo" brasileiro conhece apenas cinco modalidades de pessoas jurídicas públicas: União, Estados, Municípios, Distrito Federal e Autarquia. Coincidiria, entretanto, esse quadro com o do direito positivo francês? E com o do direito italiano? E com o do direito belga?

As pessoas jurídicas públicas podem ser estudadas pelo direito administrativo, pelo direito constitucional, pelo direito civil. Esse estudo está afeto, porém, aos Cursos de Graduação. 
Entretanto, nos Cursos de Pós-Graduação, a ótica tem de ser outra, consistindo na indagação "tanto quanto possível" completa (já que, completa, é impossível) do elenco universal das pessoas jurídicas públicas.

Quais as pessoas jurídicas públicas existentes em outros "direitos"? Quantas são essas pessoas? Terminado o levantamento, pode-se indagar: em que medida, de que modo nosso "direito" pode aproveitar os modelos consagrados e aceitos por outras Administraçōes?

Já em 1930, o direito brasileiro, posto em confronto com o direito italiano, acolhia a "entidade autárquica", a "autarquia", acabando por introduzi-la em nosso "direito positivo". Era um modelo importado.

Em nossos dias, a doutrina passou a estudar os nossos territórios federais (Amapá, Roraima, Rondônia e Fernando de Noronha) e, mais uma vez, inspirando-se e beneficiando-se com a realidade italiana, concluiu que aquelas porções de nosso território nada mais são do que autarquias geográficas ou autarquias territoriais, semelhantes às que existem na Itália. Sem o auxílio do direito comparado, isso não teria sido possível.

Para um grande jurista brasileiro, o território federal brasileiro, nada mais seria do que "possessão administrativa", inovação absurda que não encontra amparo no direito comparado.

Assim, estudando o instituto personativo, podemos ver que, em cada "direito" do sistema de base romanística, o elenco das pessoas jurídicas públicas é diverso, não coincidindo de maneira alguma, nem em número (quantitativamente), nem em qualidade (ontologicamente).

Apenas para exemplificar, de maneira esquemática, assinalaremos algumas espécies, em que se desdobra o instituto personativo, em outros "direitos" do "sistema romanístico", ou a ele ligado de certo modo:

- direito italiano: a província e a região;

- direito francês: o estabelecimento público, as coletividades territoriais;

- direito belga: os polders e os wateringues;

- direito suíço: o cantão.

Pois bem, nessa rápida e sucinta exposição, já se percebe que, do confronto de direitos, no que tange a institutos, o elenco 
universal é muito mais rico, desdobra-se em espécies muito mais variadas do que o direito pátrio.

Transcendendo o "direito local", no caso, o direito brasileiro, ponto de partida e referência para a comparação, o "direito universal" revela outras pessoas jurídicas públicas, jamais existentes, em nosso direito. $\mathrm{E}$ jamais suspeitadas pelo cultor, apenas, do direito pátrio.

A nosso ver, o método errado do Curso de Pós-Graduação consistiria em aprofundar, com maior erudição, as observações já feitas no Curso de Graduação, ao mesmo assunto, apegando-se ao restrito elenco do Código Civil pátrio e desenvolvendo verdadeiro curso monográfico, intensivo, sem ultrapassar as fronteiras do direito local.

O método correto, ao contrário, abrange e supera o quadro restrito da enumeração casuística local, saindo da fixação taxativa e procurando, em outros direitos, espécies inseridas em quadros mais amplos.

Quando, no futuro, aparecer entre nós uma espécie nova, não enquadrável nos modelos estereotipados existentes, basta uma incursão pelo direito de outros países para encontrar qual o arquétipo alienígena em que se insere a "species nova" brasileira.

\section{Confronto de "ramos do direito"}

Assim como se pode fazer o "confronto de institutos", pode-se igualmente proceder ao "confronto de ramos do direito". Podemos comparar o "direito penal" brasileiro com o "direito penal" inglês, o "direito administrativo" pátrio com o "direito administrativo" francês.

Por exemplo, o confronto entre dois "direitos administrativos", a saber, um direito qualquer do sistema de base romanística, e um direito qualquer do sistema do "common law", ou, de modo mais concreto e específico, o "direito francês" e o "direito inglês", vai revelar vários traços típicos, de um e de outro, de tal modo que se percebe, na comparação, a presença de duas realidades, de dois mundos, de dois tratamentos, de duas técnicas, de dois regimes jurídicos diversos: (a) dualidade e unidade de jurisdição, (b) responsabilidade e irresponsabilidade civil do Estado, (c) auto-executoriedade e não auto-executoriedade do ato administrativo, (d) regime estatutário e regime trabalhista do agente público, (e) irrelevância e relevância do precedente. 


\section{Confronto de "direitos"}

Pode-se, em terceiro lugar, fazer o confronto global de "direitos": "direito inglês" e "direito soviético", "direito brasileiro" e "direito francês".

Nesses casos, pode-se principiar pela ala do direito público ou pela ala do direito privado, descendo-se do gênero às espécies, ramo a ramo, até chegar-se a uma visão global e panorâmica dos "direitos" confrontados.

\section{Confronto de "sistemas jurídicos"}

Por fim, chega-se ao "sistema jurídico", à constelação de "direitos", ao grupo ou agrupamento de "direitos", ligados a matrizes comuns.

Uma primeira indagação preocupa os comparatistas: a classificação dos "sistemas jurídicos", estabelecida para o direito civil, servirá para outros ramos do direito? (Como se sabe, o direito comparado nasceu e foi estruturado por obra dos civilistas. Só mais tarde foi desenvolvido pelos comparatistas de outros ramos do direito). 0 direito público, administrativo e constitucional, aceita a classificação dos "sistemas jurídicos", estruturada para o direito privado?

Os "sistemas jurídicos" classificam-se a partir de critérios.

Poder-se-ia, por exemplo, seguindo o critério sócio-econômico-político, falar em "sistemas jurídicos ocidentais", de base capitalista que, ironicamente, os socialistas chamam de "sistemas burgueses" e "sistemas jurídicos das democracias populares", de base "socialista" de base "sócio-comunista".

Poder-se-ia falar também em sistemas de base romanística e sistemas de base não-romanística, subdividindo-se estes últimos, em sistemas do "common law" e sistema do mundo socialista, além de sistemas exóticos, impossíveis de aglutinação, por não apresentarem denominadores comuns.

De qualquer modo, seja qual for a classificação empreendida, o que interessa é o confronto de sistemas, dois a dois, como, por exemplo, o sistema do "common law" e o sistema de base romanística.

Pode-se decompor os vários "direitos", constitutivos do sistema do "common law" (inglês, norte-americano e direitos da comunidade britânica), bem como se pode decompor os vários "direitos" do sistema romanístico (francês, belga, 
italiano, lusitano, espanhol, brasileiro) e comparar, em bloco, lado a lado, paralelamente, os "direitos" constitutivos das duas constelações jurídicas, o que é o mesmo que confrontar os dois sistemas, pois quem confronta todas as partes de um todo confronta, globalmente, o todo.

\section{Cursos monográficos rotativos}

Há quatro décadas, na Faculdade de Filosofia, Ciências e Letras da Universidade de São Paulo, em todas as seções, - método empregado era o monográfico rotativo, o que se justificava, na época, em virtude da própria estruturação do curso médio e da finalidade perseguida pela nova instituição, que era a de formar professores, cientistas e pesquisadores.

Em Filosofia, por exemplo, o professor escolhia um determinado pensador - Kant - e desenvolvia-lhe a doutrina, durante o semestre. No segundo semestre, Hegel. No terceiro, Descartes. E assim por diante, rotativamente. Nas Ciências, o mesmo método. Nas Letras, o professor escolhia um prosador ou poeta, Aristóteles ou Homero, no primeiro semestre, estudando exaustivamente, todos os aspectos, da obra do autor selecionado.

O lema da Escola era: "mais método, do que conteúdo"

Hoje, no Curso de Pós-Graduação, o método monográfico local é anacrônico, no setor do conhecimento jurídico. O casuísmo é-incompatível com a formação universal do jurista. Não se justifica o estudo intensivo do direito positivo regional, da visão utilitarista imediata.

A era dos cursos monográficos está ultrapassada, o curso de direito, no Mestrado e no Doutorado, não pode circunscrever-se à mesma matéria acima do curso de bacharelado, apenas em grau "mais intenso", "mais profundo", de cunho monográfico.

\section{Conclusão}

A ótica dos cursos de Mestrado e de Doutorado não se identifica, de modo algum, com a ótica dos cursos de bacharelado. São ângulos diversos do mesmo objeto material - o direito -, em planos que se superpõem em órbitas não coincidentes.

O curso de graduação é de primeiro grau, objetivando, antes de tudo, a informação. $O$ curso de pós-graduação tem por finalidade a formação. 
O curso de graduação tem como ponto de partida o direito positivo, a lei. Depois a doutrina. Mais tarde a jurisprudência.

O curso de pós-graduação, transcendendo o plano local, procura atingir as próprias matrizes da Jurisprudência, chegando à categoria jurídica, nunc et semper, numa visão universal do modelo indiferenciado.

Lançando mão do direito comparado, que é o método de confronto de institutos, de direitos, de ramos de direitos e, por fim, de sistemas, o curso de pós-graduação em matéria jurídica, só atingirá sua finalidade última, quando deixar de lado o casuísmo, o direito nacional, o imediatismo, a pesquisa em profundidade de temas locais, já estudados, para erigir-se em plano mais alto que coloque em evidência as mais modernas conquistas da ciência do direito. 